\title{
Robust biodegradation of naproxen and diclofenac by laccase immobilized using electrospun nanofibers with enhanced stability and reusability
}

Zdarta, Jakub; Jankowska, Katarzyna; Wyszowska, Marta; Kijeska-Gawroska, Ewa; Zgoa-Grzekowiak, Agnieszka; Pinelo, Manuel; Meyer, Anne S.; Moszyski, Dariusz; Jesionowski, Teofil

Published in:

Materials Science and Engineering C

Link to article, DOI:

10.1016/j.msec.2019.109789

Publication date:

2019

Document Version

Peer reviewed version

Link back to DTU Orbit

Citation (APA):

Zdarta, J., Jankowska, K., Wyszowska, M., Kijeska-Gawroska, E., Zgoa-Grzekowiak, A., Pinelo, M., Meyer, A. S., Moszyski, D., \& Jesionowski, T. (2019). Robust biodegradation of naproxen and diclofenac by laccase immobilized using electrospun nanofibers with enhanced stability and reusability. Materials Science and Engineering C, 103, [109789]. https://doi.org/10.1016/j.msec.2019.109789

\section{General rights}

Copyright and moral rights for the publications made accessible in the public portal are retained by the authors and/or other copyright owners and it is a condition of accessing publications that users recognise and abide by the legal requirements associated with these rights.

- Users may download and print one copy of any publication from the public portal for the purpose of private study or research.

- You may not further distribute the material or use it for any profit-making activity or commercial gain

- You may freely distribute the URL identifying the publication in the public portal 


\section{Accepted Manuscript}

Robust biodegradation of naproxen and diclofenac by laccase immobilized using electrospun nanofibers with enhanced stability and reusability

Jakub Zdarta, Katarzyna Jankowska, Marta Wyszowska, Ewa Kijeńska-Gawrońska, Agnieszka Zgoła-Grześkowiak, Manuel Pinelo, Anne S. Meyer, Dariusz Moszyński, Teofil Jesionowski

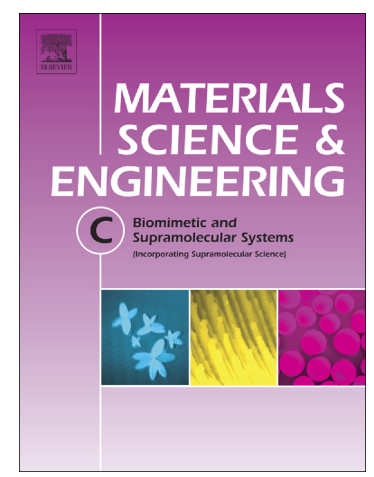

PII:

S0928-4931(19)30317-0

DOI:

Article Number: https://doi.org/10.1016/j.msec.2019.109789

Reference: 109789

To appear in: MSC 109789

Received date: Materials Science \& Engineering $C$

Revised date: 24 January 2019

Accepted date:

10 May 2019

23 May 2019

Please cite this article as: J. Zdarta, K. Jankowska, M. Wyszowska, et al., Robust biodegradation of naproxen and diclofenac by laccase immobilized using electrospun nanofibers with enhanced stability and reusability, Materials Science \& Engineering C, https://doi.org/10.1016/j.msec.2019.109789

This is a PDF file of an unedited manuscript that has been accepted for publication. As a service to our customers we are providing this early version of the manuscript. The manuscript will undergo copyediting, typesetting, and review of the resulting proof before it is published in its final form. Please note that during the production process errors may be discovered which could affect the content, and all legal disclaimers that apply to the journal pertain. 
Robust biodegradation of naproxen and diclofenac by laccase immobilized using electrospun nanofibers with enhanced stability and reusability

\author{
Jakub Zdarta $^{[\mathrm{a}]^{*},}$ Katarzyna Jankowska ${ }^{[\mathrm{a}]}$, Marta Wyszowska ${ }^{[\mathrm{a}]}$, \\ Ewa Kijeńska-Gawrońska ${ }^{[\mathrm{b}]}$, Agnieszka Zgoła-Grześkowiak ${ }^{[\mathrm{c}]}$, Manuel Pinelo ${ }^{[\mathrm{d}]}$, \\ Anne S. Meyer $^{[\mathrm{e}]}$, Dariusz Moszyński ${ }^{[\mathrm{f}]}$, Teofil Jesionowski ${ }^{[\mathrm{a}]^{*}}$ \\ ${ }^{[a]}$ Institute of Chemical Technology and Engineering, \\ Faculty of Chemical Technology, Poznan University of Technology, \\ Berdychowo 4, PL-60965 Poznan, Poland \\ ${ }^{[b]}$ Faculty of Materials Science and Engineering, \\ Warsaw University of Technology, \\ Wołoska 141, PL-02507 Warsaw, Poland \\ ${ }^{[c]}$ Institute of Chemistry and Electrochemistry,
}

Faculty of Chemical Technology, Poznan University of Technology,

Berdychowo 4, PL-60965 Poznan, Poland

${ }^{[d]}$ Department of Chemical and Biochemical Engineering,

DTU Chemical Engineering, Technical University of Denmark,

Soltofts Plads 229, DK-2800 Kgs. Lyngby, Denmark

${ }^{[e]}$ Department of Biotechnology and Biomedicine

DTU Bioengineering, Technical University of Denmark,

Soltofts Plads 229, DK-2800 Kgs. Lyngby, Denmark

${ }^{[f]}$ West Pomeranian University of Technology, Szczecin

Faculty of Chemical Technology and Engineering,

Institute of Inorganic Chemical Technology and Environment Engineering,

Pułaskiego 10, PL-70322 Szczecin, Poland

* Corresponding authors:

jakub.zdarta@put.poznan.pl and teofil.jesionowski@put.poznan.pl 


\begin{abstract}
Enzymatic biodegradation of pharmaceuticals, using enzymes such as laccase, is a green solution for the removal of toxic pollutants that has attracted growing interest over recent years. Moreover, the application of immobilized biocatalysts is relevant for industrial applications, due to the improved stability and reusability of the immobilized enzymes. Thus, in the present study, laccase was immobilized by adsorption and encapsulation using poly(1-lactic acid)-co-poly( $\varepsilon$-caprolactone) (PLCL) electrospun nanofibers as a tailor-made support. The produced biocatalytic systems were applied in the biodegradation of two commonly used anti-inflammatories, naproxen and diclofenac, which are present in wastewaters at environmentally relevant concentrations. The results showed that under optimal process conditions (temperature $25^{\circ} \mathrm{C}, \mathrm{pH} 5$ and 3 for naproxen and diclofenac respectively), even from a solution at a concentration of $1 \mathrm{mg} \mathrm{L}^{-1}$, over $90 \%$ of both pharmaceuticals was removed by encapsulated laccase in batch mode. Both immobilized enzymes also exhibited high reusability: after five reaction cycles approximately $60 \%$ and $40 \%$ of naproxen and diclofenac were removed by encapsulated and adsorbed laccase respectively. In addition, a thorough analysis was made of the products of biodegradation of the two studied pollutants. Furthermore, toxicity study of the mixture after biodegradation of the pharmaceuticals showed that the solutions obtained after the process were approximately $65 \%$ less toxic than the initial naproxen and diclofenac solutions.
\end{abstract}

Keywords: laccase, immobilization, electrospun materials, environmental pollutants, pharmaceuticals, biodegradation

\title{
1. Introduction
}

Due to its high production and consumption, pharmaceutically active compounds frequently occurred in wastewater, drinking water and even ground water at concentrations usually do not exceeding nanograms or micrograms per liter [1]. Accumulation of these compounds as well as their metabolites in water compartments in unknown and uncontrolled amounts has attracted attention as they are persistent and might have negative effect on human beings and environment. For instance long-term contact with diclofenac is associated with a serious atherothrombotic and gastrointestinal issues as well as vascular risk [2]. Moreover, the adverse effect of diclofenac on environment, such as on microbial consortia and selected aquatic organisms has been previously reported [3]. On the other hand, naproxen and its metabolites also could negatively affected on human body and caused some serious 
gastrointestinal and cardiovascular adverse effects and lead to an irreparable changes in a rover ecosystems [4]. Due to the low bioavailability and complex structure of these compounds, their biodegradation is a serious environmental challenge. Conventional treatment plants are not able to efficiently remove and have some issues, such as generation of toxic by-products and waste stream. Thus, increasing interest was focused on a sustainable biological alternative as an eco-friendly and powerful solutions [5]. As of particular interest, enzymatic-based methods should be presented, as biocatalysts can degrade a wide range of xenobiotics under mild conditions, without toxic effluents [6].

The catalytic conversion of pharmaceutical pollutants takes place by the action of fungal oxidative enzymes, such as laccases, tyrosinases and various peroxidases [7]. Laccases, however, are the most frequently applied enzymes for biodegradation of persistent compounds due to their availability, low price, low substrate specificity and high catalytic activity. There are some literature study related to the use of free laccase for degradation on anti-inflammatories. For instance, Lonappan et al., reported that laccase produced by white rot fungi Trametes versicolor, degraded over $90 \%$ of diclofenac after $48 \mathrm{~h}$ of the process [8]. In another study Aracagök et al., showed that crude laccase from Trametes trogii almost completely removed diclofenac with $97 \%$ efficiency in $48 \mathrm{~h}$ [9]. However, practical application of free enzymes suffers from their low stability and poor reusability. Enzyme immobilization is a possible approach to overcome these limitations and at the same time increase the biodegradation efficiency and enzyme reuse [10]. In the previous study it has been reported that laccase was immobilized onto polyacrylonitrile nanofibers [11], marine sponges scaffolds [12] or biochar microparticles at various organic origin [13], and efficiently used for removal of hazardous compounds. As proper selection of the support material in enzyme immobilization is the crucial affecting properties of the biocatalysts, more and more attention is paid to evaluate immobilization protocols based on using novel and tailor-made supports.

The materials produced by the electrospinning method are characterized by thin structures reaching a diameter in the range from $100 \mathrm{~nm}$ to $1 \mu \mathrm{m}$, and length to even several thousand meters [14]. One of the most important features of electrospun materials is the designed geometry in a quick and relatively cheap way [15]. Although all nanofibers combine common features, the final properties of a material depend on the polymer used to obtain electrospun materials. It should be pointed that electrospun nanofibers can be also successfully used to enzyme immobilization. The important feature of materials produced by electrospinning method is porosity, biocompatibility and a large number of functional groups on the surface of 
nanofibers. This is evidenced by the fact that it is possible to immobilize the protein by means of adsorption, encapsulation or covalent bonding on the electrospun material. A wide range of polymers are used to enzyme immobilization, and poly( $\varepsilon$-caprolactone) [16] and poly(vinyl alcohol) are one of them [17]. It is worth to paying attention that during the production of electrospun nanofibers it is possible to obtain composite which, having many functional groups, increase the affinity of the enzyme to the support, for example polycaprolactone/cellulose monoacetate [18] and poly(vinyl alcohol)/polyacrylamide [19].

Hence, in this study we aimed to evaluate novel immobilization protocol for laccase from Trametes versicolor by adsorption and encapsulation approach, using PLCL electrospun nanofibers as support material. This support was used due to its exceptional mechanical stability, numerous of functional groups facilitating stable attachment of the enzyme as well as its porosity that limit diffusional limitations and enhance activity of the biomolecules. Further, the biodegradation and conversion of diclofenac and naproxen by the biocatalytic systems obtained were investigated and the optimal process conditions for removal of both pharmaceuticals have been found during the study. Moreover, comprehensive work on characterization of degradation products and their toxicity have also been examined in details. Although degradation of pharmaceuticals by laccase has been reported, to the best of our knowledge, this is the first time, where effective removal of naproxen and diclofenac by PLCL-laccase biocatalytic systems is shown. Moreover, presented results might provide a novel and efficient technique for practical application of electrospun-based immobilized enzymes for biodegradation of hazardous pollutants from wastewaters.

\section{Materials and Methods}

\subsection{Chemicals and reagents}

Poly(l-lactic acid)-co-poly(E-caprolactone) (PLCL), laccase from Trametes versicolor (EC 1.10.3.2, $\geq 0.5 \mathrm{U} / \mathrm{mg}$ ), diclofenac sodium salt (DCF, $\geq 98 \%$ ), naproxen (NPR, $\geq 99 \%$ ) (see Fig. 1), 2,2-azinobis-3-ethylbenzothiazoline-6-sulfonate (ABTS, $\geq 99 \%$ ), Coomassie Brilliant Blue, acetate and phosphate buffers at specific $\mathrm{pH}$, analytical grade chloroform and Span 80 were supplied by Sigma-Aldrich (USA). Ethanol, methanol and $85 \% \mathrm{H}_{3} \mathrm{PO}_{4}$ (all laboratory grade) were supplied by Chempur (Poland). HPLC-grade methanol and LC-MS-grade acetonitrile were obtained from Merck (Germany). HPLC-grade water was produced in the laboratory using a Demiwa system (Watek, Czech Republic). 

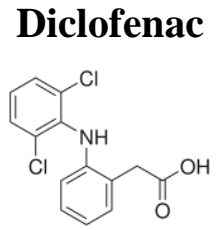

$\mathrm{pK}_{\mathrm{a}} 4.15$
Naproxen

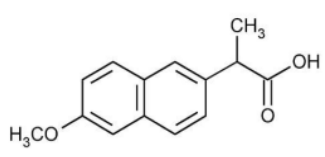

$\mathrm{pK}_{\mathrm{a}} 4.15$

Figure 1. Structures and $\mathrm{pK}_{\mathrm{a}}$ values of diclofenac and naproxen

\subsection{Fabrication of electrospun materials}

Hydrophilic PLCL nanofibers were obtained by electrospinning of an emulsion. To prepare the oil phase, $0.5 \mathrm{~g}$ of PLCL was dissolved in $5 \mathrm{~mL}$ of analytical grade chloroform to form a $10 \%(w / v)$ solution. Next, $50 \mu \mathrm{L}$ of the surfactant Span 80 was added dropwise. An acetate buffer at pH 5 was used as the water phase. The oil and aqueous solutions were mixed in a ratio of 1:20 (v/v), and the mixture was stirred at RT for $3 \mathrm{~h}$ to obtain a smooth water-in-oil emulsion. PLCL nanofibers with laccase encapsulated within the fibers were also prepared by emulsion electrospinning. The oil phase was prepared as in the case of the PLCL fibers. For the water phase, laccase was dissolved in acetate buffer at a concentration of $100 \mathrm{mg} \mathrm{mL}^{-1}$. Next, the polymer and laccase solutions were mixed in a ratio of 1:20 (v/v) and stirred for $3 \mathrm{~h}$ at RT. The electrospinning of both emulsions was carried out under the same optimized conditions using a NANON-01A apparatus (MECC Co., Japan). An 18G flattened needle connected to a syringe by a PTFE tube was fixed to a moving head with a linear speed of $50 \mathrm{~mm} / \mathrm{sec}$ and a working width of $100 \mathrm{~mm}$. A high voltage of $25 \mathrm{kV}$ was applied through the needle. The distance from the needle tip to the collector was set at $150 \mathrm{~mm}$. The feed rate was fixed at $1.5 \mathrm{~mL} \mathrm{~h}^{-1}$. Nanofibrous meshes were collected on an aluminum foil-covered, grounded steel plate collector and dried for $24 \mathrm{~h}$ in a vacuum drier $\left(25^{\circ} \mathrm{C}\right)$.

\subsection{Immobilization of laccase by adsorption on PLCL membrane}

Prior to immobilization the membrane was washed with deionized water, cut into pieces of $0.25 \mathrm{~cm}^{2}(0.5 \times 0.5 \mathrm{~cm})$ and weighed. The pieces were then immersed in $5 \mathrm{~mL}$ of $1 \mathrm{mg} \mathrm{mL}^{-1}$ laccase solution (acetate buffer at $\mathrm{pH}=5$ ) for $2 \mathrm{~h}$ at $4{ }^{\circ} \mathrm{C}$ using a KS 4000i incubator (IKA Werke GmbH, Germany). After the process, the PLCL fibers with immobilized enzyme were separated from the mixture and washed with acetate buffer to remove unbound enzyme. 


\subsection{Storage stability and kinetic parameters of free and immobilized enzymes}

The storage stability of free and immobilized enzyme stored at $4{ }^{\circ} \mathrm{C}$ was examined over 30 days. Briefly, ABTS was used as a substrate, to which $10 \mathrm{mg}$ of free or immobilized laccase was added. Changes in the concentration of the substrate were measured spectrophotometrically $(\lambda=420 \mathrm{~nm}$ ), using a Jasco V-750 (Japan) spectrophotometer. For the storage stability study, the initial value of the activity of the free or immobilized enzyme was defined as $100 \%$. The inactivation constant $\left(k_{D}\right)$, and half-life $\left(t_{1 / 2}\right)$ were evaluated based on the linear regression slope.

The same reaction was used to evaluate the kinetic parameters: the Michaelis-Menten constant $\left(K_{m}\right)$ and the maximum rate of reaction $\left(V_{\max }\right)$. For this purpose solutions of the substrate at concentrations ranging from 1 to $100 \mathrm{mM}$ were used, and the experiments were carried out under optimum assay reaction conditions. The Hanes-Woolf plot was used to calculate the apparent kinetic parameters of the free and immobilized enzyme. All measurements were made in triplicate, and the results are presented as average \pm standard deviation.

\subsection{Biodegradation of pharmaceuticals}

The biodegradation of naproxen and diclofenac by free, adsorbed and encapsulated laccase was studied using an IKA KS 4000i incubator shaker (100 rpm). To $10 \mathrm{~mL}$ of a mixture of diclofenac or naproxen in buffer solution, $5 \mathrm{mg}$ of free or immobilized laccase was added. The mixtures were then kept for $24 \mathrm{~h}$ and sampled at specified time intervals. After sampling, $0.1 \mathrm{~mL}$ of methanol was added prior to quantitative analysis. As naproxen is known for its resistance to enzymatic biodegradation [20] $0.1 \mathrm{mM}$ of ABTS was added as a mediator agent to the solutions of that pharmaceutical.

Prior to evaluation of the efficiency of pharmaceutical biodegradation, the efficiency of adsorption of naproxen and diclofenac by the electrospun materials was examined. For this purpose, $50 \mathrm{mg}$ of fibers with adsorbed and immobilized laccase were subjected to thermal deactivation $\left(4 \mathrm{~h}, 80^{\circ} \mathrm{C}\right)$ and placed in $10 \mathrm{~mL}$ of DCF and NPR solutions at concentration $1 \mathrm{mg} \mathrm{L}^{-1}$ at $\mathrm{pH} 5$ and 3 respectively. Adsorption experiments were carried out for $24 \mathrm{~h}$, and the quantity of the pharmaceuticals adsorbed onto the electrospun materials was evaluated using chromatographic techniques.

The effect of $\mathrm{pH}$ on the biodegradation efficiency was evaluated using solutions at concentration $1 \mathrm{mg} \mathrm{L}^{-1}$ at $25{ }^{\circ} \mathrm{C}$ over the $\mathrm{pH}$ range $3-7$. To adjust the $\mathrm{pH}$, a buffer solution with the desired $\mathrm{pH}$ was used. The effect of temperature on the removal efficiency was 
evaluated at temperatures of 5,25 and $50{ }^{\circ} \mathrm{C}$ using diclofenac and naproxen solutions at concentration $1 \mathrm{mg} \mathrm{L}^{-1}$ in acetate buffer at $\mathrm{pH} 5$ and 3 respectively. To assess the effect of the concentration of the pharmaceutical solution on degradation efficiency, solutions at concentrations of $0.1,1.0$ and $10.0 \mathrm{mg} \mathrm{L}^{-1}$ were used. Experiments were carried out at a temperature of $25^{\circ} \mathrm{C}$ at $\mathrm{pH} 5$ (diclofenac) and $\mathrm{pH} 3$ (naproxen).

The reusability of the adsorbed and encapsulated laccase was tested using diclofenac and naproxen solutions at concentration $1 \mathrm{mg} \mathrm{L}^{-1}$ in acetate buffer at $\mathrm{pH} 5$ and 3 respectively, at $25{ }^{\circ} \mathrm{C}$. After each biodegradation cycle, the immobilized enzymes were separated from the reaction mixture, washed with acetate buffer at the desired $\mathrm{pH}$ and placed into a fresh pharmaceutical solution. The activity of laccase in the first biodegradation cycle was defined as $100 \%$ activity. All of the above experiments were performed in triplicate, and the results are presented as average \pm standard deviation.

\subsection{Analytical procedures}

The morphology of the PLCL fibers before and after enzyme immobilization was evaluated based on SEM photographs (EVO40, Zeiss, Germany) after gold coating (Balzers PV205P, Switzerland). Individual fibers diameters were measured from the SEM micrographs of 100 randomly selected nanofibers using Image Analysis Software (ImageJ, National Institute of Health, USA). FTIR spectra were obtained using a Bruker Vertex 70 spectrometer (Germany) in the wavenumber range $4000-400 \mathrm{~cm}^{-1}$ (resolution $0.5 \mathrm{~cm}^{-1}$ ) using anhydrous $\mathrm{KBr}$ for sample preparation. The amount of immobilized enzyme $\left(\mathrm{mg} \mathrm{g}^{-1}\right)$ was determined using the Bradford method, by measuring the initial enzyme dosage and the concentration of the protein in the supernatant after immobilization, and considering the mass of the support material [21]. The surface composition of the PLCL fibers before and after enzyme immobilization was analyzed by means of X-ray photoelectron spectroscopy (XPS) applying a Prevac system (ESCA, Poland) with Scienta analyzer (SES2002, Sweden) and $\mathrm{Mg} \mathrm{K \alpha}(\mathrm{h} v=1253.7 \mathrm{eV})$ excitation radiation.

\subsection{Chromatographic measurements}

A chromatographic system from Dionex (USA) consisting of a P580 A LPG gradient pump, an ASI-100 autosampler, an STH 585 oven and an RF 2000 fluorescence detector was used for naproxen determination. $5 \mu \mathrm{L}$ samples were injected into a C18 Hypersil GOLD column $(150 \mathrm{~mm} \times 4.6 \mathrm{~mm}$ I.D.; $5 \mu \mathrm{m})$ with a $2.1 \mathrm{~mm}$ I.D. filter cartridge $(0.2 \mu \mathrm{m})$ (Thermo Scientific, USA). The mobile phase consisted of $75 \%$ methanol at a flow rate of $1.5 \mathrm{~mL} \mathrm{~min}{ }^{-1}$ 
at $35{ }^{\circ} \mathrm{C}$. Signal responses were measured by fluorescence detection at wavelengths set to $230 \mathrm{~nm}$ for excitation and $355 \mathrm{~nm}$ for emission.

The chromatographic system UltiMate 3000 RSLC (Dionex, USA) coupled to an API 4000 QTRAP triple quadrupole mass spectrometer (AB Sciex, USA) was used for diclofenac determination. $5 \mu \mathrm{L}$ samples were injected into a KinetexEvo C18 column (150 mm x $2.1 \mathrm{~mm}$ I.D.; $2.6 \mu \mathrm{m}$ ) (Phenomenex, USA) maintained at $35{ }^{\circ} \mathrm{C}$. The mobile phase employed in the analysis consisted of $0.1 \% \mathrm{HCOOH}$ in water and acetonitrile at a flow rate of $0.3 \mathrm{~mL} \mathrm{~min}{ }^{-1}$. The following gradient was used: 0 min 70\%; $2.5 \operatorname{min~100\% ;~} 3.0$ min 100\% of acetonitrile. The LC column effluent was directed to the electrospray ionization source (Turbo Ion Spray) operating in negative ion mode. The following settings were applied for the ion source and mass spectrometer: curtain gas 10 psi, nebulizer gas 40 psi, auxiliary gas 40 psi, temperature $450{ }^{\circ} \mathrm{C}$, ion spray voltage $-4500 \mathrm{~V}$, declustering potential $-45 \mathrm{~V}$, collision gas set to medium. The dwell time for each mass transition detected in the selected reaction monitoring mode was set to $200 \mathrm{~ms}$. The quantitative transition was from 294 to $250 \mathrm{~m} / \mathrm{z}$ at collision energy set to $-16 \mathrm{~V}$, and the confirmatory transition was from 294 to $214 \mathrm{~m} / \mathrm{z}$ at collision energy set to $28 \mathrm{~V}$.

Identification of degradation products was performed using the above-mentioned LC-MS system. $5 \mu \mathrm{L}$ samples were injected into a Gemini-NX C18 column (100 mm x 2.0 mm I.D.; 3 $\mu \mathrm{m}$ ) (Phenomenex, USA) maintained at $35{ }^{\circ} \mathrm{C}$. The mobile phase consisted of $5 \mathrm{mM}$ ammonium acetate in water and methanol at flow rate $0.3 \mathrm{~mL} \mathrm{~min}^{-1}$, at a gradient from $50 \%$ to $100 \%$ methanol in $4 \mathrm{~min}$ and then for $2 \mathrm{~min}$ in isocratic conditions. The electrospray ion source operated in positive and negative mode. Nitrogen was used in both the source and the mass spectrometer. The following parameters of the ESI source and mass spectrometer were used: curtain gas pressure $10 \mathrm{psi}$, nebulization gas pressure $45 \mathrm{psi}$, auxiliary gas pressure 45 psi, source temperature $450{ }^{\circ} \mathrm{C}$, ESI voltage $+/-4500 \mathrm{~V}$, declustering potential $-40 \mathrm{~V}$. Chromatograms were collected in enhanced mass spectra mode in the range 50-900 m/z.

The linearity of the methods was tested over a wide range for all analytes. The instrumental limit of detection (LOD) and the instrumental limit of quantitation (LOQ) were calculated on the basis of the signal-to-noise $(\mathrm{S} / \mathrm{N})$ ratio, using $\mathrm{S} / \mathrm{N}=3$ for calculation of the LOD and $\mathrm{S} / \mathrm{N}$ $=10$ for calculation of the LOQ. Precision and accuracy were not tested, because sample preparation included only the dilution step. Therefore, only the injection precision of the instrument is applicable in this procedure, and this was always below $1 \%$. The values obtained for diclofenac were $\mathrm{LOD}=0.09\left(\mu \mathrm{g} \mathrm{L}^{-1}\right), \mathrm{LOQ}=0.3\left(\mu \mathrm{g} \mathrm{L}^{-1}\right)$, linear range $0.5-1000$ 
$\left(\mu \mathrm{g} \mathrm{L}^{-1}\right)$; the values for naproxen were $\mathrm{LOD}=0.3\left(\mu \mathrm{g} \mathrm{L}^{-1}\right), \mathrm{LOQ}=1.0\left(\mu \mathrm{g} \mathrm{L}^{-1}\right)$, linear range $1-5000\left(\mu \mathrm{g} \mathrm{L}^{-1}\right)$.

\subsection{Toxicity tests}

The acute toxicity of the untreated solutions of naproxen and diclofenac and the solutions treated with adsorbed and encapsulated laccase was evaluated at ambient temperature using Artemia salina as the test microorganism, according to the methodology presented by Bilal et al. [22]. Briefly, the mobility rate of 48-hour-old shrimps was measured after $48 \mathrm{~h}$ of incubation in untreated and enzymatically treated solutions of the pharmaceuticals. The effective concentration $\left(\mathrm{EC}_{30}\right)$ was then calculated. $\mathrm{EC}_{30}$ is defined as the concentration of the pharmaceutical (\%) at which $30 \%$ of the target population show a positive response after the exposure time. Solutions of artificial seawater and potassium permanganate were used as the negative and positive control respectively. The toxicity tests were performed in duplicate, and results are presented as average \pm standard deviation.

\subsection{Statistical analysis}

Statistically significant differences were determined using one-way ANOVA performed in SigmaPlot 12 (Systat Software Inc., USA) using Tukey's test. Statistical significance was established at $\mathrm{p}<0.05$.

\section{Results and discussion}

\subsection{Characterization of the fibers and enzyme immobilization}

The PLCL electrospun materials before immobilization consisted of randomly arrayed linear and continuous fibers with diameters of around $0.5-1 \mu \mathrm{m}$, with a relatively uniform, folded and bead-free surface (Fig. 2a). After laccase encapsulation (Fig. 2b) the diameter of the fibers did not change significantly; however some tubercles could be observed in certain areas of the fibers and their surface was more uneven, implying effective insertion of the enzyme aggregates into the PLCL fibers. By contrast, as presented in Fig. 2c, after enzyme adsorption the total surface of the fibers became corrugated. In addition, the diameter of the fibers increased, reaching up to $2 \mu \mathrm{m}$, indicating that laccase was uniformly distributed on the surface of the fibers. In the study, also the average diameter of obtained fibers before and after laccase immobilization were calculated and reached $373 \pm 127 \mathrm{~nm} ; 469 \pm 222 \mathrm{~nm}$ and $430 \pm 143$ for crude PLCL fibers, PLCL fibers with encapsulated laccase and PLCL fibers with adsorbed laccase, respectively (Fig. 2 inset). 

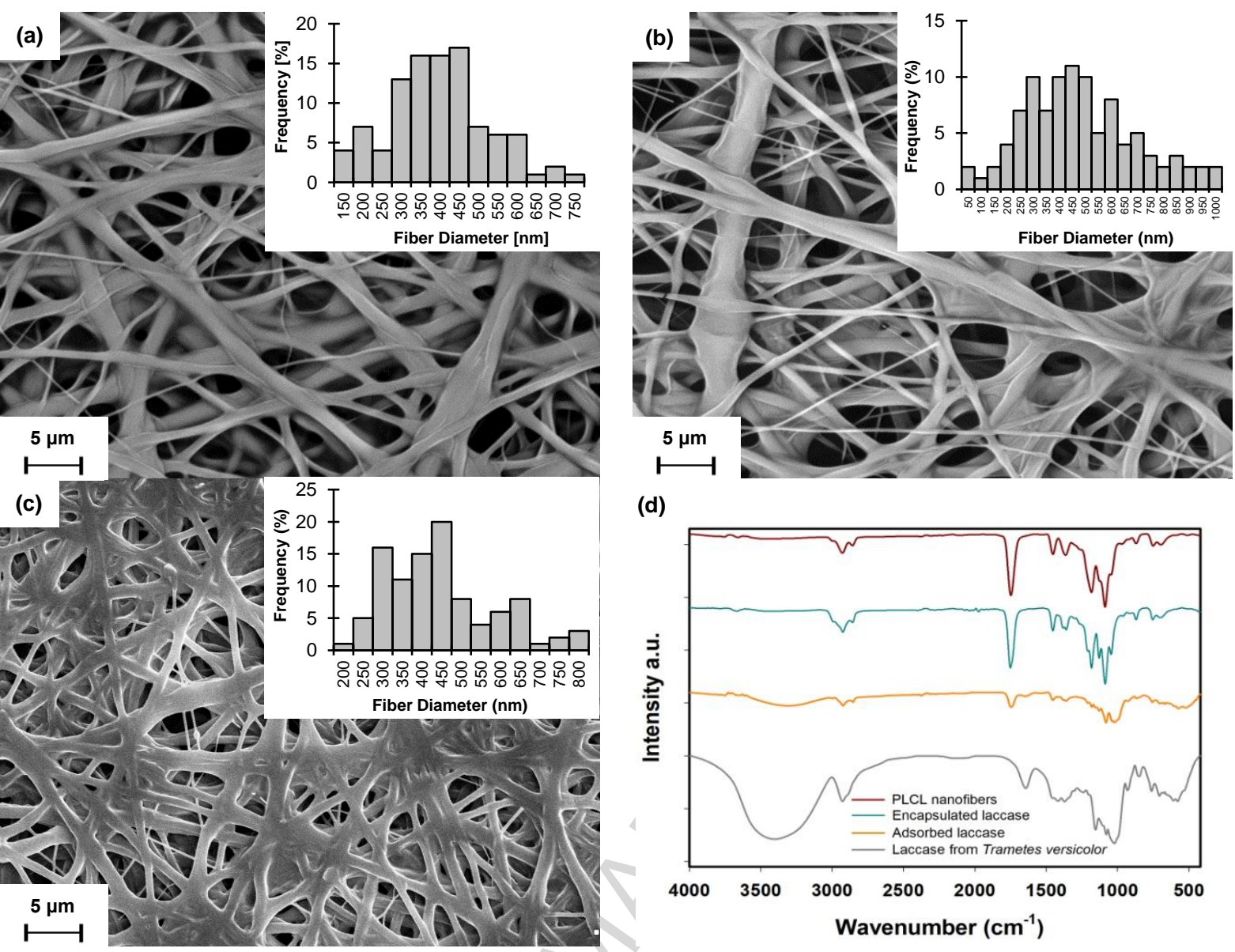

(d)

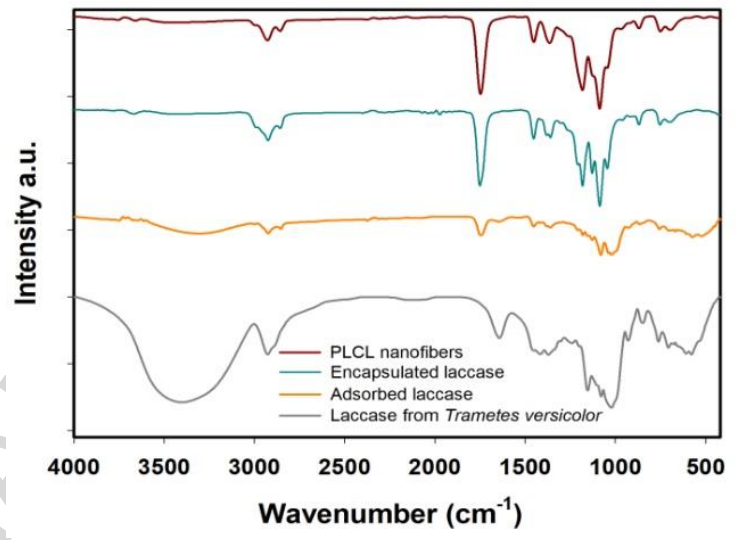

Figure 2. SEM images of (a) crude PLCL fibers, (b) PLCL fibers with encapsulated laccase, (c) PLCL with adsorbed laccase and (d) FTIR spectra of PLCL fibers before and after laccase immobilization. Inset, the diameter distribution for each types of fibers before and after laccase immobilization.

Additionally, to investigate the functional groups present in the PLCL fibers and in the products after immobilization, FTIR spectroscopy was applied. The FTIR spectrum of the pristine fibers contains signals characteristic for the $-\mathrm{CH}_{3}\left(2945 \mathrm{~cm}^{-1}\right)$, $-\mathrm{CH}_{2}\left(1395 \mathrm{~cm}^{-1}\right)$ and $\mathrm{C}-\mathrm{O}-\mathrm{C}\left(1185\right.$ and $\left.1020 \mathrm{~cm}^{-1}\right)$ groups present in the structure of PLCL. A significant peak with a maximum at $1756 \mathrm{~cm}^{-1}$ is attributed to stretching vibrations of carbonyl groups, which are responsible for enzyme binding. As expected, when laccase was encapsulated into the electrospun fibers, peaks related to the enzyme were not observed on the FTIR spectrum. However, slight shifts of the signal maxima were observed, suggesting changes in the chemical microenvironment of the PLCL moieties after enzyme encapsulation. Comparing the FTIR spectra of pristine PLCL fibers and those with adsorbed laccase, new signals appeared at $3430 \mathrm{~cm}^{-1}$ and $650 \mathrm{~cm}^{-1}$, corresponding to stretching vibrations of $-\mathrm{OH}$ 
and $-\mathrm{NH}_{2}$ groups and bending vibrations of $\mathrm{C}-\mathrm{C}$ bonds, and thus characteristic of the enzyme structure, as shown in Fig. 2d. Moreover, compared with the spectra of PLCL and free laccase, after enzyme adsorption a shift of the signal maxima towards higher wavenumbers was observed. These indicate effective adsorption immobilization, by the formation of hydrogen bonds between carbonyl groups in the PLCL fibers and amine and hydroxyl groups in the laccase structure [23].

The structure of the PLCL crude nanofibers and immobilization of laccase were followed using the surface analysis by X-ray photoelectron spectroscopy. The surface composition of PLCL fibers before immobilization, after laccase encapsulation and after enzyme adsorption was analysed. It has been found that on the surface of PLCL nanofibers before laccase immobilization mainly $\mathrm{C}-\mathrm{H}, \mathrm{C}-\mathrm{OH}$ and carboxylic groups $(\mathrm{COOH})$ occur. Furthermore, the elemental analysis of PLCL fibers and material after laccase encapsulation gives identical result. The surface of these materials is composed of about $77 \%$ of carbon atoms and about $22 \%$ of oxygen atoms. In case of the material after enzyme adsorption apart of the above mentioned elements a distinctive though low (about 0.5 at $\%$ ) signal of nitrogen was detected. Since immobilization of enzyme takes place on a surface of PLCL fibers only a presence of nitrogen atoms originating from peptide bonds is expected. Its low intensity is justified by a relatively high information depth for organic material and the fact that PLCL molecules dominates in the region of analysis. Therefore the presence of nitrogen is considered as a confirmation of successful immobilization of laccase. In the material after laccase encapsulation the outer material (PLCL fibers) screens the XPS signal from enzyme molecules inside capsules.

The high-resolution XPS N 1s spectrum from material after enzyme adsorption indicates that nitrogen atoms are in chemical environment characteristic for peptide bonds at $400.4 \mathrm{eV}$ [24]. The XPS C 1s spectra of all investigated samples are shown in Fig. 3 The spectrum of PLCL fibers is presented as a grey fill and is virtually identical with a spectrum coming from encapsulated laccase (dotted line). A spectrum originating from adsorbed laccase differs in the region about $289 \mathrm{eV}$ which is characteristic for carboxyl functional groups. The intensity of the peak in these region is lower than that from other samples. It indicates that part of the carboxylic groups from PLCL fibers is involved with the bonding of immobilized enzyme. 


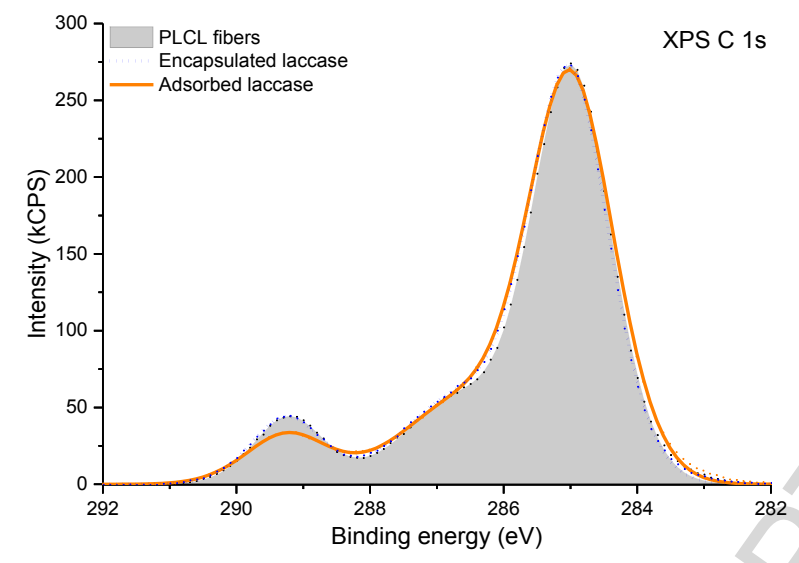

Figure 3. XPS C 1s spectra of PLCL nanofibers, PLCL nanofibers with encapsulated laccase and PLCL nanofibers with adsorbed laccase.

\subsection{Characterization of products after laccase immobilization}

According to the data in Table 1, the amount of encapsulated laccase (340 $\mathrm{mg} \mathrm{g}^{-1}$ ) was approximately $25 \%$ higher than the quantity of adsorbed laccase $\left(292 \mathrm{mg} \mathrm{g}^{-1}\right)$. This is directly related to the fact that before encapsulation the laccase was dispersed in the solution used for electrospinning, and thus the total amount of the enzyme was incorporated into the fibers. Meanwhile, during adsorption immobilization, some enzyme losses were observed, resulting in lower laccase loading.

Table 1. Laccase loading and kinetic parameters of free and immobilized laccases. Standard deviation do not exceed $5 \%$.

\begin{tabular}{cccc}
\hline Laccase & $\begin{array}{c}\text { Laccase loading } \\
\left(\mathbf{m g ~ g}^{-1} \text { fibers }\right)\end{array}$ & $\begin{array}{c}\boldsymbol{K}_{\boldsymbol{m}} \\
(\mathbf{m M})\end{array}$ & $\begin{array}{c}\boldsymbol{V}_{\max } \\
(\mathbf{m M} / \mathbf{s})\end{array}$ \\
\hline free laccase & - & 0.051 & 0.039 \\
adsorbed laccase & 292 & 0.143 & 0.033 \\
encapsulated laccase & 340 & 0.215 & 0.024 \\
\hline
\end{tabular}

In line with expectations, the Michaelis-Menten constant $\left(K_{m}\right)$ of adsorbed laccase was three times higher $(0.143 \mathrm{mM})$ and $K_{m}$ of encapsulated laccase was over four times higher $(0.215 \mathrm{mM})$, than that of the free enzyme $(0.051 \mathrm{mM})$, indicating lower substrate affinity to the enzyme after immobilization. Whereas, the maximum reaction rate $\left(V_{\max }\right)$ of both immobilized laccases was lower than that of the free enzyme. The differences in $K_{m}$ and $V_{\max }$ 
between the free and immobilized enzymes might be explained by an increase in diffusional limitations and lower accessibility of the enzyme's active sites after immobilization, caused by the spatial barriers of the matrix [25]. The effect of the diffusion limitations on $K_{m}$ is particularly pronounced for the encapsulated enzyme, as the PLCL surrounds the enzyme molecules and reduces their availability to the substrates. Nevertheless, in our study both immobilized laccases have a $V_{\max }$ value up to $75 \%$ of that of the free laccase, indicating that they can still be considered efficient catalytic systems for the removal of pharmaceuticals. The retention of such good catalytic properties, particularly in the case of encapsulated laccase, was an unexpected finding. It might be explained by the highly porous structure of the electrospun nanofibers used that partially reduces diffusional limitations, as has been reported previously [26].

\subsection{Storage stability of free and PLCL-immobilized laccase}

Irrespective of the immobilization protocol used, the storage stability of both PLCLimmobilized enzymes was significantly enhanced compared with the free laccase (Fig. 4). Accordingly, encapsulated and adsorbed laccase retained respectively over $90 \%$ and around $70 \%$ of their initial activity after 30 days of storage at $4{ }^{\circ} \mathrm{C}$. These values correspond to the inactivation constant $\left(k_{D}\right)$ of 0.004 and 0.014 1/day and enzyme half-life $\left(t_{1 / 2}\right)$ of 173.3 and 49.5 days for encapsulated and adsorbed laccase, respectively. By contrast, the free enzyme retained $60 \%$ of its initial activity after 10 days, and only around $30 \%$ after 30 days. Also noticed $k_{D}$ and $t_{1 / 2}$ of free enzyme were significantly lower, as compared to immobilized biocatalysts and reached 0.0397 1/day and 17.5 days, indicating lower stability of the free enzyme. These results might be explained by the protection of the enzyme molecules against conformational changes by the PLCL electrospun supports. Thus, better stabilization of the three-dimensional structure of the enzyme is provided. The higher activity retention in the case of the encapsulated laccase is also related to the formation of a unique core-shell structure after laccase immobilization into PLCL fibers, which protects the enzyme molecules against deactivation caused by harsh reaction conditions [27]. 


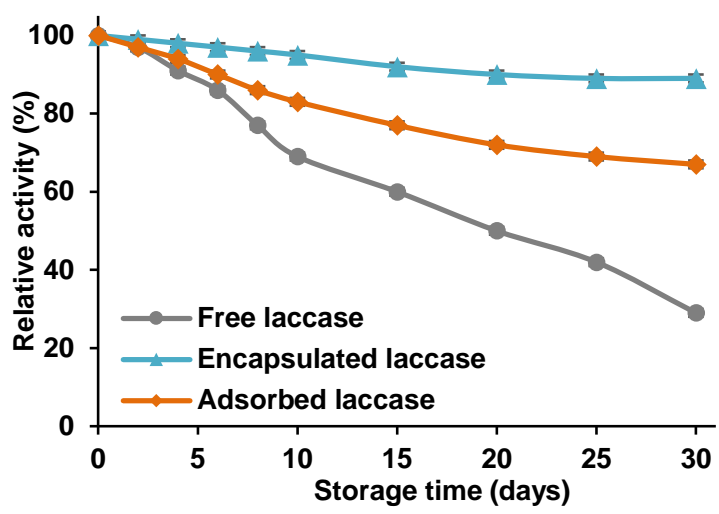

Figure 4. Storage stability of laccase from Trametes versicolor, free, encapsulated into PLCL fibres and adsorbed onto PLCL fibres.

\subsection{Biodegradation of pharmaceuticals}

It is known that the yield of enzymatic reactions is strongly affected by the process conditions. For practical applications it is important to evaluate the effect of the reaction conditions and determine the most suitable parameters for diclofenac and naproxen degradation. For this reason, the degradation experiments were carried out under various $\mathrm{pH}$ and temperature conditions. Additionally, in view of the well-developed porous structure of the electrospun fibers, the sorption capacity of the produced materials with deactivated enzyme was evaluated. In the latter case, less than $10 \%$ of both pharmaceuticals were removed from the solution by adsorption. It was thus concluded that the remediation of antiinflammatories is related mainly to the catalytic action of the immobilized laccase. Moreover, to evaluate the effect of immobilization on the catalytic properties of the laccase, biodegradation processes were carried out using the free enzyme. Under optimal conditions $\left(\mathrm{pH} 5\right.$, temperature $25^{\circ} \mathrm{C}$ ) the removal of naproxen and diclofenac by water-soluble laccase reached about $95 \%$. However, under conditions deviating from the optimum, degradation efficiencies were significantly lower than those noticed for the immobilized laccase, falling below $50 \%$ for both pharmaceuticals. Moreover, the reusability of the free biocatalyst is extremely limited.

\subsubsection{Effect of pH}

As Figure 5 shows, the highest degradation of diclofenac, around 90\%, was observed when encapsulated laccase was used in acidic conditions ( $\mathrm{pH} 3$ and 5). Degradation by adsorbed laccase in these conditions was lower, at around $60 \%$. This may be explained by the fact that the adsorbed laccase is more exposed to deactivation by the process conditions, as well as 
some enzyme leakage occured, resulting in decreased biodegradation efficiency. The optimal $\mathrm{pH}$ range of 3 to 5 for diclofenac removal may also be related to its $\mathrm{pK}_{\mathrm{a}}$ value (4.15). In this $\mathrm{pH}$ range the ratio of undissociated and dissociated molecules of diclofenac are equal; this creates the most suitable environment for the action of laccase [28]. Surprisingly, the highest rate of degradation of naproxen by the immobilized enzyme was observed at $\mathrm{pH} 3$; it reached almost $100 \%$ and around $90 \%$ for encapsulated and adsorbed laccase respectively. However, even at pH 5, PLCL-laccase systems were able to degrade over $80 \%$ of the pollutant. The shift of the optimum $\mathrm{pH}$ and significantly higher rates of biodegradation by the adsorbed enzyme, compared with the case of diclofenac, are probably related to the presence of the mediator (ABTS in this study) in the reaction mixture, which slightly altered the microenvironment around the active sites of the enzyme and suppressed the laccase deactivation process [29]. The presence of the mediator is required to achieve satisfactory rates of reaction, as it is known that naproxen is insufficiently oxidized by the laccase and is resistant to enzymatic degradation [20]. The significant drop in the rates of degradation of both anti-inflammatory drugs at $\mathrm{pH} 7$ is related to the formation of hydroxide ions, which can bind to the T2/T3 copper ions in the laccase structure. This causes the internal transfer of electrons from T1 to T2/T3 to be blocked, so that the reduction potential of oxygen is decreased and in consequence the reaction efficiency is reduced [30].
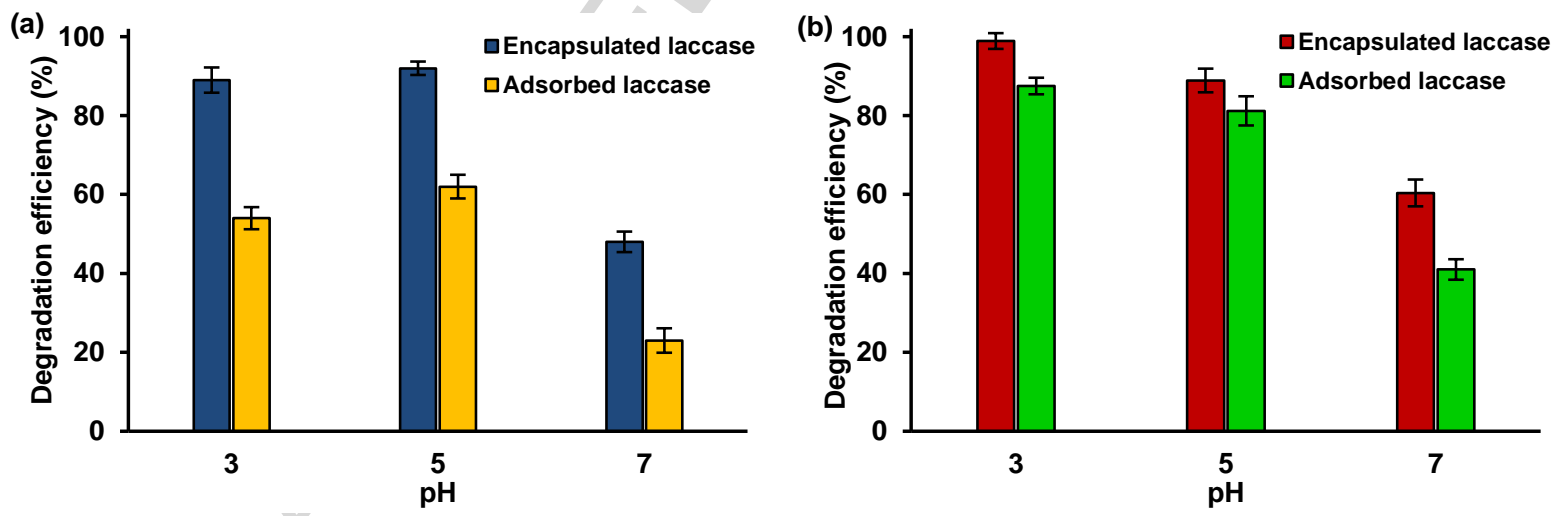

Figure 5. Effect of solution pH on efficiencies of removal of: (a) diclofenac and (b) naproxen by encapsulated and adsorbed laccase. Degradation conditions: temperature $25{ }^{\circ} \mathrm{C}$, pharmaceutical concentration $1.0 \mathrm{mg} \mathrm{L}^{-1}$.

Nevertheless, it should be emphasized that both immobilized laccases exhibited higher removal rates at strongly acidic $(\mathrm{pH} 3)$ and even neutral $\mathrm{pH}$, compared with the free enzyme (data not presented), indicating the lower sensitivity of the bound enzymes to changes in $\mathrm{pH}$. 
This is probably due to the rigidification of the enzyme structure after immobilization and its better protection against conformational changes and chemical deactivation [31].

\subsubsection{Effect of temperature}

As it can be seen in Fig. 6, degradation of naproxen and diclofenac increased with an increase in temperature, reaching a maximum at $25{ }^{\circ} \mathrm{C}(92 \%$ and $99 \%$ respectively for encapsulated laccase, $62 \%$ and $87 \%$ for adsorbed laccase), and decreasing slightly at $50{ }^{\circ} \mathrm{C}$. On the one hand, the lower degradation rates of both pharmaceuticals observed at $5{ }^{\circ} \mathrm{C}$ are related to inhibition of the enzyme and its insufficient activation. On the other hand, the high removal efficiencies observed even at $50{ }^{\circ} \mathrm{C}$ indicate that the negative effect of high temperature on the catalytic properties of the immobilized enzyme was strongly reduced. This might be related to the stabilization of the laccase structure after immobilization that prevent against conformational changes, as well as to the protective effect of the PLCL electrospun fibers. High degradation efficiencies at higher temperatures are also related to the better solubility and mobility of the pharmaceuticals at elevated temperatures, as well as reduced diffusional limitations of the substrate molecules [32]. However, it should be noted that the temperature of real effluents containing pharmaceuticals is usually in the range $15-35{ }^{\circ} \mathrm{C}$ [33]; thus, the high degradation efficiencies observed at 25 and $50{ }^{\circ} \mathrm{C}$ indicate that the resistance of the enzyme to thermal deactivation was improved after immobilization and suggesting the possible practical application of the produced biocatalytic systems for wastewater treatment.
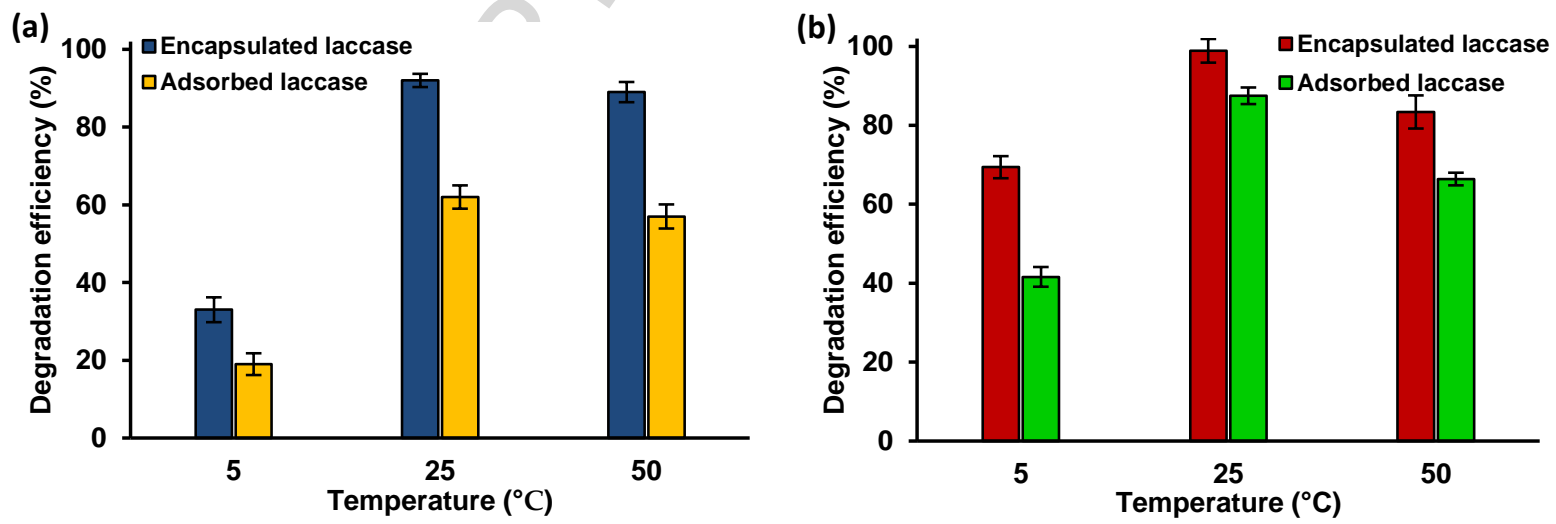

Figure 6. Effect of process temperature on the efficiency of removal of: (a) diclofenac and (b) naproxen by encapsulated and adsorbed laccase. Degradation conditions: pharmaceutical concentration $1.0 \mathrm{mg} \mathrm{L}^{-1}$, pH 5 and 3 respectively for diclofenac and naproxen. 


\subsubsection{Effect of pharmaceutical solutions concentration}

After determining the optimal $\mathrm{pH}$ and temperature conditions for the remediation processes (temperature $25^{\circ} \mathrm{C}$, pH 5 and 3 for diclofenac and naproxen respectively), we also examined how the concentration of the anti-inflammatory drugs affected the efficiency of their remediation (Fig. 7). Although the concentration of both compounds in municipal and pharmaceutical wastewaters is usually at levels of $\mu g \mathrm{~L}^{-1}$ [34] we decided to test higher concentrations to determine whether the produced biocatalytic systems offer good potential for the bioconversion of hazardous pollutants from wastewaters. As expected, the higher is the concentration of the pharmaceutical, the lower is the degradation efficiency. This might be explained by two main factors: (i) insufficient amount of the immobilized enzyme and (ii) inhibition of the laccase active sites by substrates molecules, observed at higher concentrations of pharmaceutical. Similarly as in the previous experiments, in case of both analyzed compounds, encapsulated laccase is characterized by significantly higher biodegradation ability. However, less significant drop of the removal rates was observed during degradation of diclofenac (80\% of diclofenac removal from $10 \mathrm{mg} \mathrm{L}^{-1}$ solution), compared to naproxen conversion, that is directly related to the presence of the mediator (ABTS) in the reaction mixture, which generates radical species. These radical species enhance biodegradation rate by the increasing of the laccase redox potential and reduce steric hindrances [35].

(a)

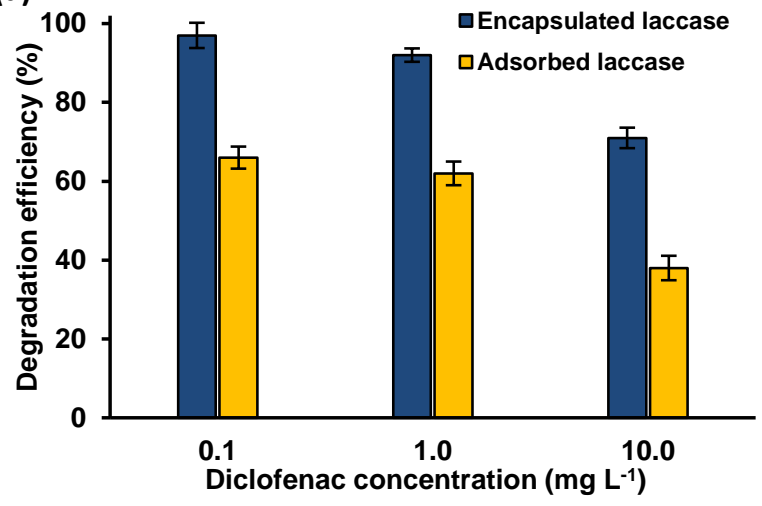

(b)

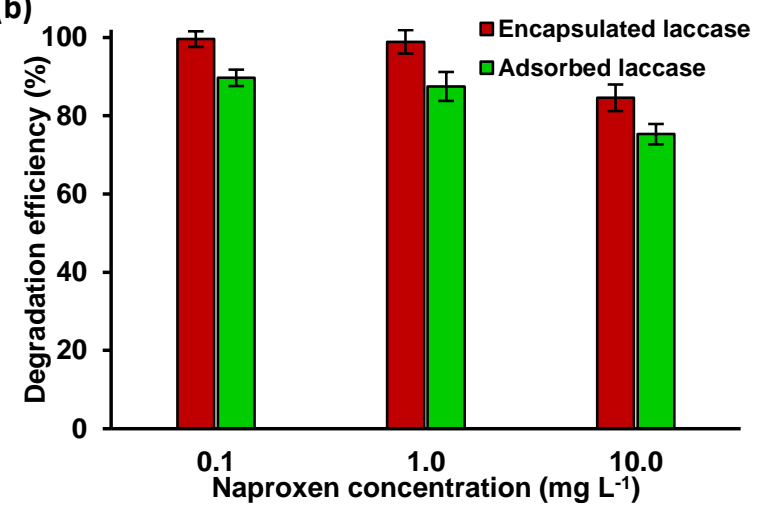

Figure 7. Effect of initial concentration of (a) diclofenac and (b) naproxen solution on the efficiency of their removal by encapsulated and adsorbed laccase. Degradation conditions: temperature $25^{\circ} \mathrm{C}$, pH 5 and 3 respectively for diclofenac and naproxen. 
(a)

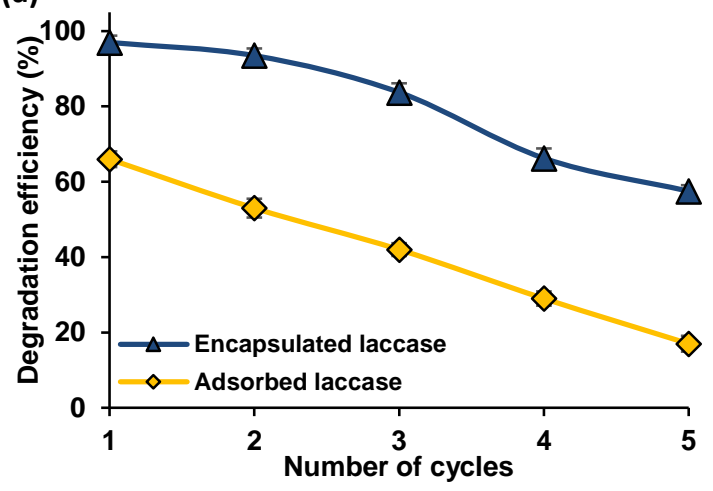

(b)

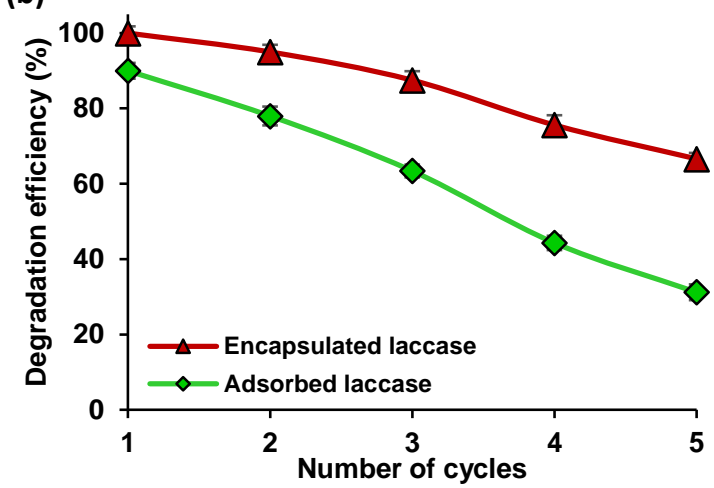

Figure 8. Reusability of the encapsulated and adsorbed laccase for degradation of (a) diclofenac and (b) naproxen over five removal cycles. Degradation conditions: temperature $25{ }^{\circ} \mathrm{C}$, pharmaceutical concentration $1.0 \mathrm{mg} \mathrm{L}^{-1}, \mathrm{pH} 5$ and 3 respectively for diclofenac and naproxen.

Reusability is the main advantage of immobilized enzymes, and is particularly important for practical applications. Hence, the operational stability of the encapsulated and adsorbed laccase was determined over five successive cycles of diclofenac and naproxen degradation (Fig. 8). The degradation of diclofenac and naproxen by adsorbed laccase followed the same trend, reaching approximately $20 \%$ and $40 \%$ respectively in the fifth reaction cycle. The sharp drop in the removal efficiency of the adsorbed enzyme is caused by laccase leakage (about $50 \%$ of the enzyme. As expected, encapsulated laccase demonstrated significantly higher reusability, enabling the removal of over $60 \%$ of diclofenac and $70 \%$ of naproxen in the fifth cycle. This is directly related to the effect of the core-shell structure of the PLCL nanofibers, which protects enzyme molecules against conformational changes caused by the external environment. Nevertheless, the activity of both immobilized laccases may also decline due to thermal and chemical denaturation and deactivation and due to partial inhibition of the biomolecules by the biodegradation products, as previously mentioned.

\subsection{Products of biodegradation and reaction pathways}

During the study, the degradation products of diclofenac and naproxen were identified by analyzing the mixture obtained after the process that resulted in the highest efficiency of degradation. Characteristic ions of diclofenac were found at a retention time of $2.6 \mathrm{~min}$, namely the pseudomolecular ion (at $\mathrm{m} / \mathrm{z}=296$ ) due to its incomplete conversion, and its 
daughter ions formed after elimination of the water molecule (at $\mathrm{m} / \mathrm{z}=278$ ), the carbon monoxide molecule (at $\mathrm{m} / \mathrm{z}=250$ ) and the chlorine radical (at $\mathrm{m} / \mathrm{z}=215$ ). Two degradation products were identified at retention times of 3.6 and 4.0 min (Fig. 9a). The first was formed after elimination of the water molecule from diclofenac, and the pseudomolecular ion of this compound (found at $\mathrm{m} / \mathrm{z}=278$ ) has the same structure as the first fragmentation ion of diclofenac. Further fragmentation ions were not found due to the low concentration of this degradation product and the rapid formation of the second bioconversion product, whose structure was confirmed by the presence of the pseudomolecular ion (at $\mathrm{m} / \mathrm{z}=284$ ) and two abundant daughter ions formed after elimination of the hydrogen peroxide molecule (at $\mathrm{m} / \mathrm{z}=250$ ) and the chlorine radical (at $\mathrm{m} / \mathrm{z}=215$ ). Surprisingly, results show that hydroxy- and dihydroxydiclofenac (products of enzymatic conversion of diclofenac) were not detected, indicating the transformation of diclofenac into non-detected metabolites, as presented also earlier $[8,36]$.

In the second test, apart from the naproxen peak at retention time $2.2 \mathrm{~min}$, a number of other compounds were found and identified (Fig. 9b). The degradation process of naproxen led to the elimination of the formic acid molecule from the carboxylic group of naproxen. As a result three different degradation products were found: two formed immediately and one after oxidation of the carbon atom adjacent to the aromatic ring. For the first two compounds detected at retention times 2.1 and $3.3 \mathrm{~min}$, only the pseudomolecular ion at $\mathrm{m} / \mathrm{z}=185$ was found, due to their relatively stable nature under soft electrospray ionization. The first of these compounds had a similar retention time to naproxen and the same $\mathrm{m} / \mathrm{z}$ value as the daughter ion of naproxen. It was identified as a degradation product because during the test the pseudomolecular ion of naproxen (at $\mathrm{m} / \mathrm{z}=231$ ) completely disappeared. The initially determined ratio of the ions at $\mathrm{m} / \mathrm{z}=231$ to those at $\mathrm{m} / \mathrm{z}=185$, equal to $3: 4$, is characteristic of naproxen in the given LC-MS system and the conditions of the analytical method. The disappearance of the first peak with simultaneous increase in the second is evidence of the formation of a new product found at a similar retention time. Unfortunately, due to lack of further fragmentation, the compounds eluted at retention times 2.1 and 3.3 min could not be distinguished from each other and assigned reliably to peaks. The third degradation product was found at retention time $2.6 \mathrm{~min}$. The pseudomolecular ion of this compound found at $\mathrm{m} / \mathrm{z}=201$ was decomposed by the loss of the ketene molecule, leading to an ion at $\mathrm{m} / \mathrm{z}=159$. Thus, 1-(6-metoxynaphtalen-2-yl)ethanone was determined to be the main degradation product formed in the presence of laccase in our study. Moreover, as the test with naproxen was performed with the ABTS mediator, this compound was also present in the 
chromatogram. More interestingly, there were two ions found which may be attributed to conjugation products of the naproxen molecule with the ABTS molecule and a large part of that molecule. These two ions were found at retention times $1.4 \mathrm{~min}($ at $\mathrm{m} / \mathrm{z}=715$ ) and $1.8 \mathrm{~min}($ at $\mathrm{m} / \mathrm{z}=458$ ) respectively. These conjugation products of naproxen and ABTS mediator have not previously been reported in literature. In the course of the degradation, only the first can potentially be transformed back to ABTS. The formation of the second results in an inevitable loss of ABTS and a potentially lower rate of degradation of naproxen due to the lower concentration of the mediator.

(a)
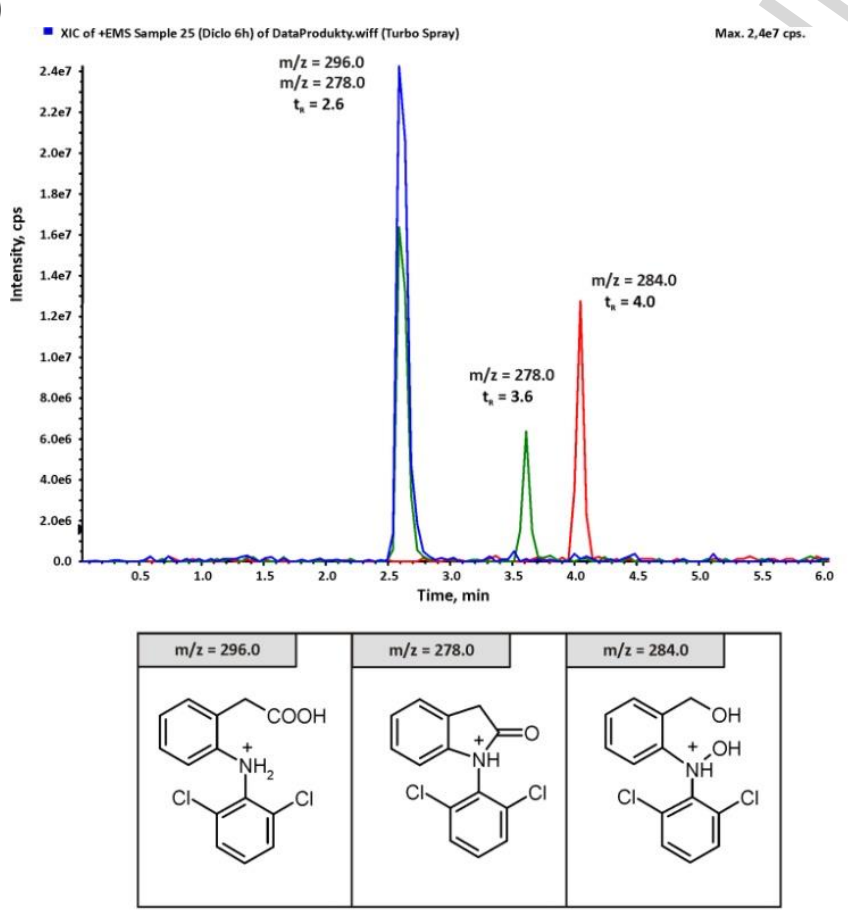
(b)
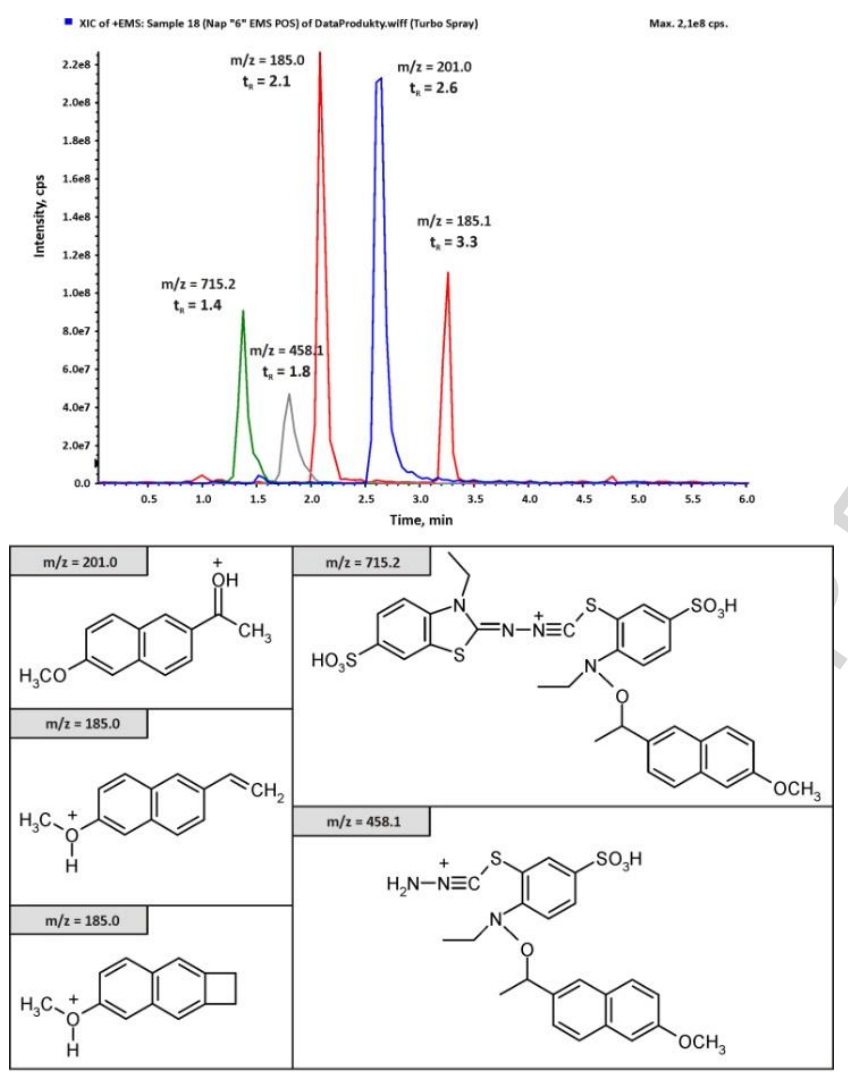

Figure 9. Extracted ion chromatogram after $6 \mathrm{~h}$ of biodegradation by encapsulated laccase of (a) diclofenac and (b) naproxen. The structures of ions found at retention times (a) 2.6, 3.6 and 4.0 min after diclofenac degradation and (b) 1.4, 1.8, 2.1, 2.6 and $3.3 \mathrm{~min}$ after naproxen degradation are given below the chromatogram.

\subsection{Toxicity study}

One of the most important objectives in research related to the removal of pollutants is to reduce the toxicity of the effluent after treatment. Thus, ecotoxicity studies against $A$. salina were carried out, to evaluate changes in the toxicity of the untreated and enzymatically treated solutions of both pharmaceuticals. For this purpose, mixtures produced after $24 \mathrm{~h}$ of biodegradation under optimal process conditions, were examined. The results are presented in terms of $\mathrm{EC}_{30}(\%)$, the concentration of the pollutant at which $30 \%$ of the microorganisms showed a positive response after the exposure time (Fig. 10).

The untreated diclofenac and naproxen solutions have $\mathrm{EC}_{30}$ values of around $25 \%$ and $20 \%$, indicating the high toxicity of both pharmaceutical solutions. After enzymatic treatment by both biocatalytic systems, the toxicity was substantially reduced, with $\mathrm{EC}_{30}$ ranging from $60 \%$ to around $85 \%$. However, the use of encapsulated laccase led to higher $\mathrm{EC}_{30}$ values (79.6\% and $84.7 \%$ for diclofenac and naproxen respectively) than in the case of the adsorbed enzyme. This suggests the lower toxicity of the effluent, and is consistent with the results 
obtained for biodegradation efficiency, which showed the removal rate to be higher when the encapsulated biocatalyst was used. The decrease in the toxicity of the tested solutions may be explained by the elimination of both anti-inflammatories from the mixture by way of enzymatic conversion [37]. It has been shown that both native laccase and laccase-containing fungal strains may be used for the removal of hazardous pharmaceuticals from wastewaters; however, monitoring of the toxicity of the effluents is key to determining the practical application of the evaluated methods, as intermediates and/or final products might be even more toxic than the initial compounds [38]. Nevertheless, the higher values of $\mathrm{EC}_{30}$ obtained suggest that the products of biodegradation are in fact less toxic than the initial solutions of the tested pharmaceuticals. Thus, our findings show that the use of laccase immobilized on electrospun PLCL nanofibers is a very promising choice for the effective biodegradation and detoxification of naproxen and diclofenac from water solutions, and may lead to practical applications.

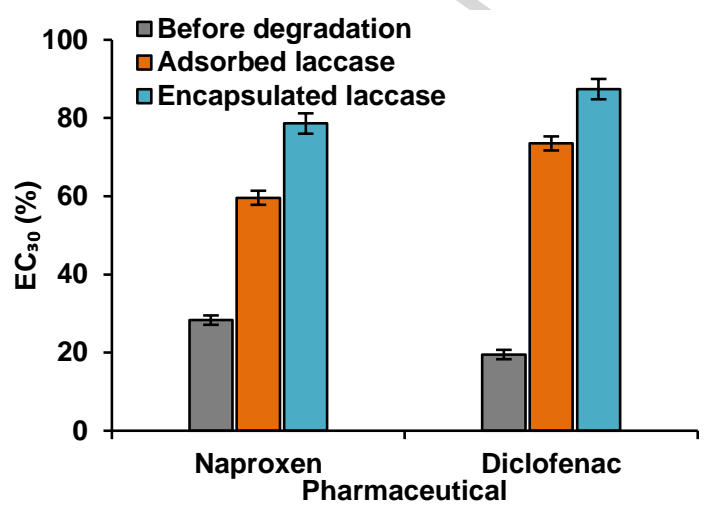

Figure 10. Toxicity study of untreated solutions of naproxen and diclofenac and solutions treated with immobilized laccase, using the A. salina test. $\mathrm{EC}_{30} \geq 100 \%=$ nontoxic.

\section{Conclusions}

The main obstacles to the widespread implementation of laccase-based systems for biodegradation of hazardous pollutants, including various pharmaceutical compounds, are the cost of the enzyme and its poor reusability. Thus, in the present study, we have demonstrated a proof-of-concept for the use of PLCL electrospun fibers as a support material for the adsorption and encapsulation of laccase, an enzyme of enormous environmental potential, and an application of the obtained biocatalytic systems in the removal of naproxen and diclofenac from water solutions. After $24 \mathrm{~h}$ of the process, encapsulated laccase biodegraded over $90 \%$ of naproxen and diclofenac under optimal process conditions, namely a temperature of $25^{\circ} \mathrm{C}$ 
and $\mathrm{pH}$ of 5 and 3 respectively, from a solution at an environmentally relevant concentration $\left(1 \mathrm{mg} \mathrm{L}^{-1}\right)$. The efficiency of removal of both compounds by the adsorbed enzyme was lower, mainly due to deactivation of the enzyme and its elution from the support. The obtained biocatalytic systems exhibited excellent operational stability: even after five consecutive degradation cycles the encapsulated laccase removed over $60 \%$ of the pollutants, which is of particular interest for practical applications. Furthermore, the storage stability of the immobilized laccase was significantly better than that of the free enzyme. Finally, we identified products of the enzymatic conversion of both anti-inflammatories, and showed them to be substantially less toxic than the parent compound. It should be added that the metabolites formed might be easily removed from water solutions using simple physical processes, such as precipitation. In summary, the presented results illustrate the excellent potential of PLCL-immobilized laccase for the removal of pharmaceuticals from aqueous solutions, and indicate the possibility of its practical application in real wastewater treatment on an industrial scale. However, further studies in this area are still needed.

Acknowledgements: This research was funded by Ministry of Science and Higher Education (Poland) as financial subsidy to PUT.

Declarations of interest: none. 


\section{References:}

[1] J.B. Costa, M.J. Lima, M.J. Sampaio, M.C. Neves, J.L. Faria, S. Morales-Torres, A.P.M. Tavares, C.G.Silva, Enhanced biocatalytic sustainability of laccase by immobilization on functionalized carbon nanotubes/polysulfone membranes, Chem. Eng. J. 355 (2019) 974-985. https://doi.org/10.1016/j.cej.2018.08.178

[2] L. Lloret, G. Eibes, T.A. Lú-Chau, M.T. Moreira, G. Feijoo, J.M. Lema, Laccasecatalyzed degradation of anti-inflammatories and estrogens, Biochem. Eng. J. 51 (2010) 124131. https://doi.org/10.1016/j.bej.2010.06.005.

[3] N. Vieno, M. Sillanpää, Fate of diclofenac in municipal wastewater treatment plant - A review. Environ. Int. 69 (2014) 28-39. https://doi.org/10.1016/j.envint.2014.03.021.

[4] E. Marco-Urrea, M. Pérez-Tujillo, P. Blánqez, T. Vicent, G. Caminal, Biodegradation of the analgesic naproxen by Tramates versicolor and identification of intermediates using HPLC-DAD-MS and NMR, Bioresour. Technol. 101 (2010) 2159-2166. https://doi.org/10.1016/j.biortech.2009.11.019.

[5] L. Lonappan, Y. Liu, T. Rouissi, F. Pourcel, S.K. Brar, M. Verma, R.Y. Surampallic, Covalent immobilization of laccase on citric acid functionalized micro-biochars derived from different feedstock and removal of diclofenac, Chem. Eng. J. 351 (2018) 985-994. https://doi.org/10.1016/j.cej.2018.06.157.

[6] J. Zdarta, A.S Meyer, T. Jesionowski, M. Pinelo, Developments in support materials for immobilization of oxidoreductases: A comprehensive review, Adv. Colloid Interface Sci. 258 (2018) 1-20. https://doi.org/10.1016/j.cis.2018.07.004.

[7] G. Wu, X. Liu, P. Zhou, L. Wang, M. Hegazy, X. Huang, Y. Huang, A facile approach for the reduction of 4- nitrophenol and degradation of congo red using gold nanoparticles or laccase decorated hybrid inorganic nanoparticles/polymer-biomacromolecules vesicles, Mat. Sci. Eng. C. 94 (2019) 524-533. https://doi.org/10.1016/j.msec.2018.09.061

[8] L. Lonappan, T. Rouissi, M.A. Laadila, S.K. Brar, L.H. Galan, M. Verma, R.Y. Surampalli, Agro-industrial-produced laccase for degradation of diclofenac and identification of transformation products, ACS Sustain. Chem. Eng. 5 (2017) 5772-5781. https://doi.org/10.1021/acssuschemeng.7b00390.

[9] Y.D. Aracagök, H. Göker, N. Cihangir, Biodegradation of diclofenac with fungal strains, Arch. Environ. Prot. 44 (2018) 55-62. https://doi.org/10.24425/118181.

[10] T. Jesionowski, J. Zdarta, B. Krajewska, Enzyme immobilization by adsorption: A review, Adsorption 20 (2014) 801-821. https://doi.org/10.1007/s10450-014-9623-y. 
[11] R. Xu, C. Chi, F. Li, B. Zhang, Laccase-polyacrylonitrile nanofibrous membrane: Highly immobilized, stable, reusable, and efficacious for 2,4,6-trichlorophenol removal. ACS Appl. Mater. Interfaces 5 (2013) 12554-12560. https://doi.org/10.1021/am403849q.

[12] J. Zdarta, K. Antecka, R. Frankowski, A Zgoła-Grześkowiak, H. Ehrlich, T. Jesionowski, The effect of operational parameters on the biodegradation of bisphenols by Trametes versicolor laccase immobilized on Hippospongia communis spongin scaffolds, Sci. Total. Environ. 615 (2018) 784-795. https://doi.org/10.1016/j.scitotenv.2017.09.213.

[13] L. Lonappan, Y. Liu, T. Rouissi, S.K. Brar, M. Verma, R.Y. Surampalli, Adsorptive immobilization of agro-industrially produced crude laccase on various micro-biochars and degradation of diclofenac, Sci. Total. Environ. 640-641 (2018) 1251-1258. https://doi.org/10.1016/j.scitotenv.2018.06.005.

[14] E. Kijeńska, W. Święszkowski, General requirements of electrospun materials for tissue engineering: Setups and strategy for successful electrospinning in laboratory and industry, in: T. Uvar, E. Kny (Eds.), Electrospun Materials for Tissue Engineering and Biomedical Applications: Research Design and Commercialization, Elsevier, Cambridge, 2017, pp. 4356.

[15] E. Kijeńska, M.P. Prabhakaran, W. Święszkowski, K.J. Kurzydłowski, S. Ramakrishna, Electrospun bio- composite P(LLA- CL)/collagen I/collagen III scaffolds for nerve tissue engineering, J. Biomed. Mater. Res. Part B: Appl. Biomater. 100 (2012) 1093-1102. https://doi.org/10.1002/jbm.b.32676.

[16] M.F. Canbolat, H.B. Savas, F. Gultekin, Enzymatic behavior of laccase following interaction with $\gamma$-CD and immobilization into PCL nanofibers, Anal. Biochem. 528 (2017) 13-18. https://doi.org/10.1016/j.ab.2017.04.005.

[17] S.E. Rodríguez-de Luna, I.E. Moreno-Cortez, M.A. Garza-Navarro, R. Lucio-Porto, L. López Pavón, V.A. González-González, Thermal stability of the immobilization process of horseradish peroxidase in electrospun polymeric nanofibers, J. Appl. Polym. Sci. 134 (2017) article number 44811. https://doi.org/10.1002/app.44811.

[18] Y. Aykut, T. Sevgi, E. Demirkan, Cellulose monoacetate/polycaprolactone and cellulose monoacetate/polycaprolactam blended nanofibers for protease immobilization. J. Appl. Polym. Sci. 134 (2017) article number 45479. https://doi.org/10.1002/app.45479.

[19] Z. Temoçin, M. Inal, M. Gökgöz, M. Yiğitoğlu, Immobilization of horseradish peroxidase on electrospun poly(vinyl alcohol)-polyacrylamide blend nanofiber membrane and its use in the conversion of phenol, Polym. Bull. 75 (2018) 1843-1865. https://doi.org/10.1007/s00289-017-2129-5. 
[20] L.N. Nguyen, F.I. Hai, J.A. McDonald, S.J. Khan, W.E. Price, L.D. Nghiem, Continuous transformation of chiral pharmaceuticals in enzymatic membrane bioreactors for advanced wastewater treatment, Water Sci. Technol. $76 \quad$ (2017) 1816-1826. https://doi.org/10.2166/wst.2017.331.

[21] M.M. Bradford, A rapid and sensitive method for the quantitation of microgram quantities of protein utilizing the principle of protein-dye binding, Anal. Biochem. 72 (1976) 248-254. https://doi.org/10.1016/0003-2697(76)90527-3.

[22] M. Bilal, H.M.N. Iqbal, H. Hu, W. Wang, X. Zhang, Enhanced bio-catalytic performance and dye degradation potential of chitosan-encapsulated horseradish peroxidase in a packed bed reactor system, Sci. Total Environ. 575 (2017) 1352-1360. https://doi.org/10.1016/j.scitotenv.2016.09.215.

[23] E. Fatarella, D. Spinelli, M. Ruzzantea, R. Pogni, Nylon 6 film and nanofiber carriers: Preparation and laccase immobilization performance, J. Mol. Catal. B: Enzym. 102 (2014) 41-47. https://doi.org/10.1016/j.molcatb.2014.01.012.

[24] J. Zdarta, M. Wysokowski, M. Norman, A. Kołodziejczak-Radzimska, D. Moszyński, H. Maciejewski, H. Ehrlich, T. Jesionowski, Candida antarctica Lipase B immobilized onto chitin conjugated with poss ${ }^{\circledR}$ compounds: useful tool for rapeseed oil conversion, Int. J. Mol. Sci. 17 (2016) 1581-1597. https://doi.org/10.3390/ijms17091581.

[25] Q. Feng, X. Xia, A. Wei, X. Wang, Q. Wei, D. Huo, A. Wei, Preparation of Cu(II)chelated poly(vinyl alcohol) nanofibrous membranes for catalase immobilization, J. Appl. Polym. Sci. 120 (2011) 3291-3296. https://doi.org/10.1002/app.33493.

[26] A. Greiner, J.H. Wendorff, Electrospinning: A fascinating method for the preparation of ultrathin fibers, Angew. Chem. Int. Ed. 46 (2017) 5670-5703. https://doi.org/10.1002/anie.200604646.

[27] Y. Dai, L. Yin, J. Niu, Laccase-carrying electrospun fibrous membranes for adsorption and degradation of PAHs in shoal soils, Environ. Sci. Technol. 45 (2011) 10611-10618. https://doi.org/10.1021/es203286e.

[28] J. Margot, J. Maillard, L. Rossi, D.A. Barry, C. Holliger, Influence of treatment conditions on the oxidation of micropollutants by Trametes versicolor laccase, New Biotechnol. 30 (2013) 803-813. https://doi.org/10.1016/j.nbt.2013.06.004.

[29] B.S. Wolfenden, R.L. Willson, 1982. Radical-cations as reference chromogens in kinetic studies of ono-electron transfer reactions: Pulse radiolysis studies of 2,2'azinobis-(3ethylbenzthiazoline-6-sulphonate), J. Chem. Soc., Perkin Trans. 2 (1982) 805-812. https://doi.org/10.1039/P29820000805. 
[30] P.J. Strong, H. Claus, Laccase: A review of its past and its future in bioremediation, Crit. Rev. Environ. Sci. Technol. 41 (2011) 373-434. https://doi.org/10.1080/10643380902945706. [31] L.N. Nguyen, F.I. Hai, A. Dosseto, C. Richardson, W.E. Price, L.D. Nghiem, Continuous adsorption and biotransformation of micropollutants by granular activated carbon-bound laccase in a packed-bed enzyme reactor, Bioresour. Technol. 210 (2016) 108-116. https://doi.org/10.1016/j.biortech.2016.01.014.

[32] S. Georgieva, T. Godjevargova, D.G. Mita, N. Diano, C. Menale, C. Nicolucci, C.R. Carratelli, L. Mita, E. Golovinsky, Non-isothermal bioremediation of water polluted by phenol and some of its derivatives by laccase covalently immobilized on polypropylene membranes, J. Mol. Catal. B: Enzym. 66 (2010) 210-218. https://doi.org/10.1016/j.molcatb.2010.05.011.

[33] K. Hilden, T.K. Hakala, P. Maijala, T.K. Lundell, A. Hatakka, Novel thermotolerant laccases produced by the white-rot fungus Physisporinus rivulosus, Appl. Microbiol. Biotechnol. 77 (2007) 301-309. https://doi.org/10.1007/s00253-007-1155-x.

[34] L. Lonappan, S.K. Brar, R.K. Das, M. Verma, R.Y. Surampalli, Diclofenac and its transformation products: Environmental occurrence and toxicity - A review, Environ. Int. 96 (2016) 127-138. https://doi.org/10.1016/j.envint.2016.09.014.

[35] L.N. Nguyen, F.I Hai, W.E. Price, F.D. Leusch, F. Roddick, H.H. Ngo, W. Guo, S.F. Magram, L.D. Nghiem, The effects of mediator and granular activated carbon addition on degradation of trace organic contaminants by an enzymatic membrane reactor, Bioresour. Technol. 167 (2014) 169-177. https://doi.org/10.1016/j.biortech.2014.05.125.

[36] E. Marco-Urrea, M. Pérez-Tujillo, C. Cruz-Morató, G. Caminal, T. Vicent, Degradation of the drug sodium diclofenac by Tramates versicolor pellets and identification of some intermediates by NMR, J. Hazard. Mat. $176 \quad$ (2010) 836-842. https://doi.org/10.1016/j.jhazmat.2009.11.112.

[37] M. Bilal, H.M.N Iqbal, S.Z.H. Shah, H. Hu, W. Wang, X. Zhang, Horseradish peroxidase-assisted approach to decolorize and detoxify dye pollutants in a packed bed bioreactor, J. Environ. Manage. $183 \quad$ (2016) 836-842. https://doi.org/10.1016/j.jenvman.2016.09.040.

[38] C. Cruz-Morató, D. Lucas, M. Llorca, S. Rodriguez-Mozaz, M. Gorga, M. Petrovic, D. Barceló, T. Vincet, M. Sarrà, E. Marco-Urrea, Hospital wastewater treatment by fungal bioreactor: Removal efficiency for pharmaceuticals and endocrine disruptor compounds, Sci. Total. Environ. 493 (2014) 365-376. https://doi.org/10.1016/j.scitotenv.2014.05.117. 


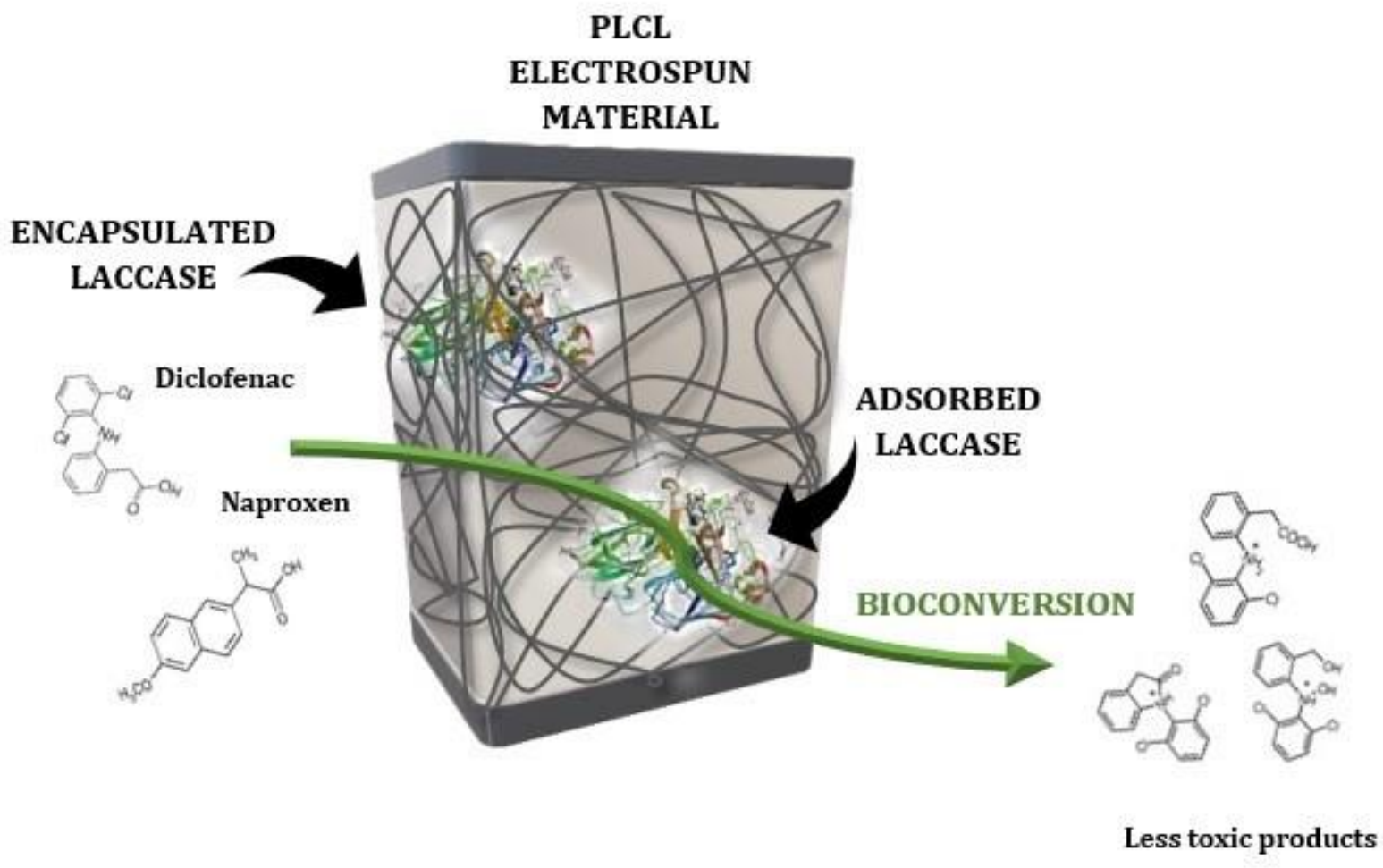

Graphical abstract 


\section{Highlights:}

- Use of electrospun PLCL nanofibers as effective support for laccase immobilization.

- Application of PLCL-laccase systems for removal of diclofenac and naproxen.

- Evaluation of optimal biodegradation conditions for the highest removal efficiency.

- Improvement of storage stability and reusability of immobilized laccase.

- Decrease in the toxicity of the solutions after biodegradation. 